\title{
Physicochemical characteristics and antiproliferative and antioxidant activities of Moroccan Zantaz honey rich in methyl syringate
}

\author{
Youssef Elamine $^{\mathrm{a}, \mathrm{b}, *}$, Badiaa Lyoussi $^{\mathrm{a}}$, Maria G. Miguel $^{\mathrm{c}}$, Ofélia Anjos ${ }^{\mathrm{d}, \mathrm{e}, \mathrm{f}}$, Letícia Estevinho ${ }^{\mathrm{g}}$, \\ Manuel Alaiz ${ }^{\mathrm{b}}$, Julio Girón-Calle ${ }^{\mathrm{b}}$, Jesús Martín ${ }^{\mathrm{h}}$, Javier Vioque ${ }^{\mathrm{b}}$ \\ ${ }^{a}$ Laboratory of Natural Substances, Pharmacology, Environment, Modeling, Health and Quality of Life (SNAMOPEQ), University of Sidi Mohamed Ben Abdellah, Fez 30 \\ 000, Morocco \\ ${ }^{\mathrm{b}}$ Instituto de la Grasa (C.S.I.C.), Universidad Pablo de Olavide, Edificio 46, Carretera de Utrera, km 1, 41013-Sevilla, Spain \\ ${ }^{\mathrm{c}}$ Mediterranean Institute for Agriculture, Environment and Development, Universidade do Algarve, Faculdade de Ciências e Tecnologia, Edificio 8, Campus de Gambelas, \\ 8005-139 Faro, Portugal \\ ${ }^{\mathrm{d}}$ Instituto Politécnico de Castelo Branco, 6001-909 Castelo Branco, Portugal \\ e Centro de Estudos Florestais, Instituto Superior de Agronomia, Universidade de Lisboa, Tapada da Ajuda, 1349-017 Lisboa, Portugal \\ ${ }^{\mathrm{f}}$ Centro de Biotecnologia de Plantas da Beira Interior, 6001-909 Castelo Branco, Portugal \\ ${ }^{8}$ Centro de Investigação de Montanha, Instituto Politécnico de Bragança, 5300-252 Bragança, Portugal \\ ${ }^{\text {h }}$ Fundación MEDINA, Avda del Conocimiento 34, 18016-Granada, Spain
}

A R T I C L E I N F O

\section{Keywords:}

Zantaz honey

Methyl syringate

Antiproliferative activity

Antioxidant activity

\begin{abstract}
A B S T R A C T
Zantaz honey is a monofloral variety produced from the melliferous plant Bupleurum spinosum (Apiaceae), a shrub that grows mainly in the Atlas Moroccan Mountains. Determination of the polyphenol composition revealed that methyl syringate accounts for more than $50 \%$ of total polyphenols, which represents a very useful parameter for the characterization of this monofloral honey. Epicatechin, syringic acid and catechin are also abundant. Caco-2 and THP-1 cells were used for determination of antioxidant and antiproliferative activities in Zantaz honey, respectively. All six commercial samples that were used for these studies exhibited antioxidant activity and inhibited cell proliferation. Interestingly, these activities had a positive correlation mainly with the content in methyl syringate and gallic acid. The recognition of health promoting activities in Zantaz honey should increase its commercial value, which would have a positive economic impact on the poor rural communities of Morocco where it is produced.
\end{abstract}

\section{Introduction}

Nowadays, research in new functional foods is a leading tendency in food chemistry. This trend is encouraged by scientific results showing that food may be an important factor in preventing diseases such as cancer and cardiovascular and neurodegenerative diseases (Bach-Faig, Berry, Lairon, Reguant, Trichopoulou, Dernini, Medina, Padulosi, et al., 2011). For example, honey is a potential functional food due to its contents in bioactive compounds, such as polyphenols, with health promoting properties.

Honey contains a very complex mixture of components because of the great variety of plants that provide nectar and pollen. Sugars represent the major component of honey, including around $75 \%$ monosaccharides, $10-15 \%$ disaccharides and small amounts of other sugars (Missio, Gauche, Gonzaga, Carolina, \& Costa, 2016). Minor compounds include polyphenols, vitamins, enzymes, amino acids, minerals, organic acids and volatiles. The composition in bioactive components of honey is mostly determined by its botanical origin (Chen et al., 2018). Hence, the most important bioactive fraction in honey is made up of secondary metabolites that are present in nectar, including phenolic acids and flavonoids (Cianciosi et al., 2018). These bioactive compounds are responsible for antibacterial, antifungal, wound healing and other properties (Cianciosi et al., 2018) in different honeys. Antiproliferative, immunomodulatory and antioxidant activities in several cancer cells have also been reported (Porcza, Simms, \& Chopra, 2016).

Bupleurum spinosum (Apiaceae) is a prickly shrub that is mostly found growing at altitudes higher than $2000 \mathrm{~m}$ in the Atlas Moroccan Mountains, although it is also present in mountainous regions of Algeria and Southern Spain (Elamine et al., 2018). Honey from this melliferous plant is dark coloured and is known as Zantaz, Zandaz, Zentaz,

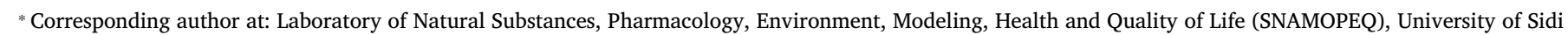
Mohamed Ben Abdellah, Fez 30 000, Morocco.

E-mail address: youssef.elamine@usmba.ac.ma (Y. Elamine). 
Aguerbaz and Airbaz honey in Morocco, referring to the Amazigh name of B. spinosum. A preliminary study showed that chemical antioxidant activity in this honey might represent a health-promoting property concerning oxidative stress involving diseases (Elamine et al., 2018). Determination of the phenolic composition of Zantaz honey may be useful to explore potential new biological activities, as well as for the characterization of the botanical origin of other plants participating in the production of this honey.

Cell-based assays are used to determine the bioactivity of functional compounds such as polyphenols because they provide a lot more information than chemical assays and can also provide information on bioavailability (Wan, Liu, Yu, Sun, \& Li, 2015). Honey can be assayed directly, or as an alternative their bioactive compounds can be extracted and assayed separately (Ahmed \& Othman, 2013; Jaganathan \& Mandal, 2009).

The first goal of the present work was determining the physicochemical properties of Zantaz honey, especially the polyphenol composition that is likely responsible for most of the bioactivity in honey. The second goal was the determination of possible antioxidant and antiproliferative properties using Caco- 2 and THP- 1 cell cultures, respectively, in order to determine the potential functional value of this honey. A third goal was to determine whether there are any correlations between biological activity and physicochemical characteristics of Zantaz honey samples.

\section{Material and methods}

\subsection{Materials and reagents}

2,7-dichlorofluorescein diacetate (DCFH-DA), 2,2'-Azo-bis-aminopropane (ABAP) and 3-(4,5-dimethylthiazol-2-yl)-2,5-diphenyltetrazolium bromide (MTT) were purchased from Sigma-Aldrich (St. Louis, MO, USA). Hanks' Balanced Salt Solution (HBSS), fetal bovine serum (FBS) and Dulbecco's modified Eagle's medium (DMEM), and other cell culture reagents were purchased from Gibco (Invitrogen, Barcelona, Spain). Methyl syringate, epicatechin, syringic acid, catechin, 4-coumaric acid, gallic acid, quercetin, apigenin, luteolin, kaempferol, naringenin, formononetin, genistein, 3-coumaric acid, daidzein, pelargonidin, 2-coumaric acid, biochanin A and cyanidin were purchased from Sigma. Ultrapure water was obtained using a Milli-Q system (Millipore, Bedford, MA, USA) and methanol, acetonitrile and 2-propanol were purchased from Teknokroma (Barcelona, Spain). All other chemicals were of analytical grade.

\subsection{Zantaz honey samples and melissopalynology}

Six honey samples ( $500 \mathrm{~g}$ ) were purchased to Moroccan beekeepers in Fez and Taza regions. To confirm the botanical origin of those samples, an analysis of pollen species was accomplished following the International Commission for Bee Botany (ICBB) method, as described previously (Louveaux, Maurizio, \& Vorwohl, 1978) An optic microscope (Leitz Messtechnik GmbH, Wetzlar, Germany) with $400 \times$ and $1000 \times$ objectives, was used for pollen identification and count. One thousand pollen grains were counted for each sample, and the frequent classes were determined twice. Only species present at average frequencies that consider them as dominant (more than $45 \%$ ), secondary (between $16 \%$ and $45 \%$ ) and important minor pollen (from 3 to 15\%) were considered for the present study.

\subsection{Zantaz honey samples and physicochemical characterization}

Free acidity, pH, lactonic acidity, ash content, electrical conductivity, moisture content and diastase activity were determined according to procedures recommended by the International Honey Commission (Bogdanov et al., 1997). Colour and melanoidins contents were determined as previously described (Elamine et al., 2019).

\subsection{Determination of sugars composition}

Sugars (fructose, glucose, sucrose, melezitose, turanose, maltose, arabinose, melibiose and trehalose) were determined by Reverse Phase High Performance Liquid Chromatography (RP-HPLC) using a refraction index detector and commercial standards (Bogdanov et al., 1997). One gram of honey was weighed and dissolved in $500 \mathrm{~mL}$ ultra-pure water. One millilitre of this solution was diluted to $200 \mathrm{~mL}$ with ultrapure water. Samples were filtered through $0.20 \mu \mathrm{m}$ GHP Acrodisk $^{\circledR}$ membrane (Pall Life Sciences, USA). An analytical stainless-steel column (Purospher ${ }^{\oplus} \mathrm{STAR}-\mathrm{NH}_{2}$ with $4 \mathrm{~mm}$ diameter, $250 \mathrm{~mm}$ length and $5 \mu \mathrm{m}$ particle size) and acetonitrile / water $(80 / 20, \mathrm{v} / \mathrm{v})$ at $1.3 \mathrm{~mL} /$ min flow rate were used. The column and detector cell were kept at $30{ }^{\circ} \mathrm{C}$ and the injection volume was $10 \mu \mathrm{l}$.

\subsection{Determination of polyphenols composition}

Samples of honey were prepared for analysis according to Salamanca \& Torres, (2017). Briefly, samples (0.5 g honey in $1 \mathrm{~mL}$ methanol) were vortexed until complete dissolution and centrifuged $(12.000 \mathrm{~g})$ prior to RP-HPLC injection $(20 \mu \mathrm{l})$. Analysis of polyphenols was carried out by RP-HPLC and detection at $254 \mathrm{~nm}$, using an Ultrasphere ODS column ( $4.6 \mathrm{~mm} \times 250 \mathrm{~mm}, 5 \mu \mathrm{m}$ particle size) (BeckmanCoulter, CA, USA). Elution of polyphenols was carried out at $1 \mathrm{~mL} / \mathrm{min}$ with the following gradient of methanol in water adjusted to $\mathrm{pH} 3$ with phosphoric acid: 0 to $70 \mathrm{~min}$, gradient from 0 to $70 \%$ methanol; 70 to $75 \mathrm{~min}, 70 \%$ methanol; 75 to 80 min gradient to $100 \%$ methanol; 80 to $85 \mathrm{~min}, 100 \%$ methanol. Polyphenols were identified by comparison of retention times with those of standards. Some polyphenols were identified by LC/HRMS using an Agilent 1200 Rapid Resolution HPLC interfaced to a Bruker maXis mass spectrometer as described by PérezVictoria, Martín, \& Reyes (2016). The Chapman and Hall Dictionary of Natural Products database was used for the identification of these compounds. Those identifications were further confirmed using commercial standards.

\subsection{Cell culture}

THP-1, a monocyte-like cell line, derived from an acute monocytic leukemia (M5 subtype) and Caco-2 cells, derived from a colon carcinoma, were obtained from the European Cell Culture Collection and cultured under standard cell culture conditions $\left(5 \% \mathrm{CO}_{2}\right.$ at $\left.37{ }^{\circ} \mathrm{C}\right)$ in DMEM medium supplemented with $10 \%$ of foetal bovine serum, $1 \%$ of non-essential amino acids, $100 \mathrm{U} / \mathrm{mL}$ of penicillin and $100 \mathrm{mg} / \mathrm{mL}$ of streptomycin. Caco-2 cells were subcultured once a week and medium was replaced once between subcultures. THP-1 cells were subcultured three times a week by dilution in fresh medium. Dilutions when cells were subcultured was adjusted as necessary in order to keep cell concentrations within the ranges recommended by the supplier.

\subsection{Assay of antiproliferative activity}

THP-1 cells were seeded in 96-well microplates $\left(10^{4}\right.$ cells/well) in the presence of Zantaz honey at concentrations from 0.02 to $0.10 \mathrm{~g} / \mathrm{mL}$ and incubated for 24 and $72 \mathrm{~h}$ in standard cell culture conditions. After incubation, cells were exposed to MTT for $1 \mathrm{~h}$ by addition of fresh medium containing the reagent so that the final concentration of MTT was $0.5 \mathrm{mg} / \mathrm{mL}$. Reduced MTT was solubilized by addition of the same volume of $0.1 \mathrm{~N} \mathrm{HCl}$ in isopropanol (Girón-Calle, Alaiz, \& Vioque, 2010). Absorbance at $570 \mathrm{~nm}$ with a background reference wavelength of $630 \mathrm{~nm}$ was measured using a Multiscan microplate reader (Waltham, MA, United States).

An MTT blank consisting of the same components as above in the absence of cells was carried out since it was observed that honey reduces MTT (see below Results and discussion section). Hence, cell viability using the MTT assay was determined after substruction of this 
blank from the values obtained with the cells incubated with honey samples. Results are shown as percentage of control (no honey addition). IC $_{50}$ values were calculated after plotting cell viability versus honey concentration. Results are the average of five replicates.

\subsection{Assay of antioxidant activity}

The Caco- 2 cell line, derived from a human colon tumour, was used to determine the antioxidant activity of Zantaz honey samples. The production of free radicals induced by treatment of the cells with (ABAP) was determined with the dichlorofluorescein (DCF) assay (Wang \& Joseph, 1999). Cells were seeded in 96 well microplates $\left(10^{4}\right.$ cells/well) and incubated until reaching confluence. Honey samples (between $20 \mathrm{mg} \mathrm{mL}^{-1}$ and $160 \mathrm{mg} \mathrm{mL}^{-1}$ ) were then added to the cells after complete removal of the medium and the plates were incubated in the same condition for $24 \mathrm{~h}$. Growth medium was removed, and wells were washed with HBSS before addition of DCFH-DA (100 $\mu \mathrm{l}, 25 \mu \mathrm{M}$ in HBSS). Plates were preincubated at $37^{\circ} \mathrm{C}$ for $1 \mathrm{~h}$ and washed with HBSS $(100 \mu \mathrm{l})$ followed by addition of $285 \mu \mathrm{M}$ ABAP in HBSS $(100 \mu \mathrm{l})$. Fluorescence (excitation at $485 \mathrm{~nm}$, emission at $555 \mathrm{~nm}$ ) was measured every $10 \mathrm{~min}$ for $180 \mathrm{~min}$ in a Fluoroskan Ascent plate-reader (Thermo Scientific, MA, USA). Each plate included a positive control (cells treated with DCFH-DA and ABAP) and negative control (cells treated only with DCFH-DA). The negative control was included in order to prevent overestimation of free radicals due to photo oxidation of DCFH. Lower fluorescence emission in the presence of honey indicates a lower free radical generation due to the antioxidant activity of Zantaz honey. Cellular antioxidant activity (CAA) was calculated as shown in the equation: CAA unit $=100-\left(\mathrm{AUC}_{\mathrm{s}} / \mathrm{AUC}_{\mathrm{c}}\right) \times 100$, where $\mathrm{AUC}_{\mathrm{c}}$ is the integrated area under the curve for control (no sample) and $\mathrm{AUC}_{\mathrm{s}}$ is integrated area under the curve for honey samples. A calibration curve obtained with quercetin was used to express CAA as quercetin equivalents.

\subsection{Statistical analysis}

One way ANOVA followed by a post-hoc Tukey test was carried out using IBM SPSS statistics 25. Differences with $\mathrm{p}<0.05$ were considered significant. Independent student $t$ tests were used for comparison of two groups. Principal component analysis (PCA) was used for multivariate analysis using MATLAB 2018a software. The IC $_{50}$ values for the antiproliferative activity are given as $1 / \mathrm{IC}_{50}$ to avoid negative correlation with antiproliferative compounds and simplify interpretation of results.

\section{Results and discussion}

\subsection{Mellissopalynology and physicochemical characterization of Zantaz honey}

Table 1 shows the pollen analysis and physicochemical characteristics of the six Zantaz honey samples used in this study. B. spinosum plant as a source of pollen and nectar was confirmed after pollen analysis. B. spinosum pollen was the most abundant pollen in all honey samples with an average of $60 \%$. Its frequencies ranged between $51 \%$ and $80 \%$. Other important pollen species in Zantaz honey were Cytisus sp (Fabaceae), Populus sp (Salicaceae) and Eragrostis pilosa (Poaceae) with average values of $12 \%, 8 \%$ and $6 \%$ respectively.

From a quality point of view, all physicochemical values are within international standards (Council Directive 2001/110/EC, 2002). Average ash content and conductivity are below the maximum values allowed, $0.6 \%$ and $800 \mu \mathrm{S} / \mathrm{cm}$, respectively. Diastase activity was well above 8 shade units/g, which is required to assure honey authenticity and indicates that honey was not heat processed or subjected to inadequate storage conditions. Water content was lower than the maximum value allowed for honey, $20 \%$, although water in some of the
Table 1

Pollen analysis and physicochemical characteristics of Zantaz honey samples. Results are the average \pm sd of six samples. tr: traces.

\begin{tabular}{|c|c|c|c|c|}
\hline & Parameter & Mean \pm sd & Min & Max \\
\hline Pollen analysis & $\begin{array}{l}\text { Bupleurum } \\
\text { spinosum } \\
\text { (Apiaceae) }\end{array}$ & $60 \pm 11$ & 51 & 80 \\
\hline \multirow[t]{4}{*}{ (\%) } & $\begin{array}{l}\text { Cytisus sp. } \\
\text { (Fabaceae) }\end{array}$ & $12 \pm 18$ & 0 & 38 \\
\hline & $\begin{array}{l}\text { Populus sp. } \\
\text { (Salicaceae) }\end{array}$ & $8 \pm 2$ & 5 & 11 \\
\hline & $\begin{array}{l}\text { Eragrostis pilosa } \\
\text { (Poaceae) }\end{array}$ & $6 \pm 6$ & 0 & 14 \\
\hline & Others & $14 \pm 10$ & 1 & 29 \\
\hline \multirow[t]{10}{*}{$\begin{array}{l}\text { Physicochemical } \\
\text { characteristics }\end{array}$} & $\begin{array}{l}\text { Conductivity ( } \mu \mathrm{s} / \\
\mathrm{cm})\end{array}$ & $429.16 \pm 55.78$ & 351.66 & 527.00 \\
\hline & Ash (\%) & $0.18 \pm 0.03$ & 0.13 & 0.22 \\
\hline & $\mathrm{pH}$ & $3.99 \pm 0.18$ & 3.78 & 4.22 \\
\hline & $\begin{array}{l}\text { Free acidity } \\
(\mathrm{mEq} / \mathrm{Kg})\end{array}$ & $19.21 \pm 4.14$ & 14.70 & 26.20 \\
\hline & $\begin{array}{l}\text { Lactonic acidity } \\
(\mathrm{mEq} / \mathrm{Kg})\end{array}$ & $11.92 \pm 0.73$ & 11.00 & 13.00 \\
\hline & $\begin{array}{l}\text { Total acidity } \\
(\mathrm{mEq} / \mathrm{Kg})\end{array}$ & $15.56 \pm 2.20$ & 12.85 & 19.10 \\
\hline & $\begin{array}{l}\text { Diastase activity } \\
\text { (shade number) }\end{array}$ & $22.12 \pm 4.32$ & 15.82 & 29.52 \\
\hline & Melanoidins & $1.09 \pm 0.13$ & 0.86 & 1.25 \\
\hline & $\begin{array}{l}\text { Colour (mm } \\
\text { Pfund) }\end{array}$ & $67.65 \pm 7.56$ & 51.93 & 74.25 \\
\hline & Water (\%) & $19.86 \pm 0.92$ & 18.40 & 21.13 \\
\hline \multirow[t]{8}{*}{ Minerals (mg/Kg) } & $\mathrm{K}$ & $572.35 \pm 94.69$ & 429.15 & 694.71 \\
\hline & $\mathrm{Ca}$ & $153.49 \pm 16.23$ & 124.15 & 170.73 \\
\hline & $\mathrm{Na}$ & $52.96 \pm 12.50$ & 38.39 & 77.69 \\
\hline & $\mathrm{Mg}$ & $32.19 \pm 9.43$ & 24.35 & 52.80 \\
\hline & $\mathrm{Fe}$ & $15.32 \pm 2.93$ & 11.52 & 18.23 \\
\hline & $\mathrm{Cu}$ & $1.32 \pm 0.32$ & 0.89 & 1.80 \\
\hline & Mn & $0.88 \pm 0.20$ & 0.51 & 1.12 \\
\hline & $\mathrm{Zn}$ & $0.56 \pm 0.22$ & 0.35 & 0.88 \\
\hline \multirow[t]{9}{*}{ Sugars $(\mathrm{g} / 100 \mathrm{~g})$} & Fructose & $38.7 \pm 2.65$ & 33.52 & 41.83 \\
\hline & Glucose & $22.15 \pm 1.27$ & 19.61 & 23.42 \\
\hline & Melibiose & $2.84 \pm 1.00$ & 1.44 & 4.28 \\
\hline & Turanose & $1.9 \pm 0.11$ & 1.77 & 2.05 \\
\hline & Arabinose & $1.69 \pm 0.78$ & $\operatorname{tr}$ & 2.44 \\
\hline & Maltose & $1.63 \pm 0.67$ & 0.95 & 3.03 \\
\hline & Trehalose & $1.03 \pm 0.46$ & 0.68 & 2.03 \\
\hline & Melezitose & $0.19 \pm 0.22$ & $\operatorname{tr}$ & 0.51 \\
\hline & Sucrose & $\mathrm{tr}$ & $\operatorname{tr}$ & $\operatorname{tr}$ \\
\hline
\end{tabular}

samples was slightly higher. $\mathrm{pH}$ ranged from 3.8 to 4.2 and total acidity was within the required limits.

Sugars represent the main fraction in honey and determine its nutritional value. Fructose and glucose were the most abundant sugars, which is consistent with previous studies of Zantaz honey (Elamine et al., 2018). The contents in sucrose were below 5\%, which is the maximum sucrose content generally allowed in honey (Council Directive 2001/110/EC, 2002). High sucrose contents are indicative of honey adulteration. The Zantaz honey samples showed also none or very low amounts of the trisaccharide melezitose. High melezitose contents are indicative of the presence of honeydew (Bogdanov, Uoffa \& Ddob, 2004).

The contamination of nectar by soil surrounding apiaries is the main source of minerals in honey. Hence, mineral composition may be used to determine the geographical origin of honey (Pasquini et al., 2014). The mineral content in Zantaz honey shown in Table 1 is in agreement with previous reports concerning Zantaz honey (Elamine et al., 2019).

Polyphenols constitute a very heterogeneous class of compounds that can be divided into flavonoids and non-flavonoids (mainly phenolic acids) and are very important from a functional point of view (Cianciosi et al., 2018). Flavonoids and non-flavonoids are used to determine the botanical origin of honey, especially in the case of monofloral honeys (Bertoncelj, Polak, Kropf, Korošec, \& Golob, 2011). Nineteen polyphenols were found in Zantaz honey by RT-HPLC analysis 
Table 2

Polyphenol composition of Zantaz honey samples. Results are the average \pm sd of two determinations.

\begin{tabular}{|c|c|c|c|c|c|c|c|c|c|}
\hline Polyphenols (mg/Kg) & $\mathrm{H} 1$ & $\mathrm{H} 2$ & H3 & $\mathrm{H} 4$ & H5 & H6 & Means $\pm S D$ & Min & Max \\
\hline Methyl syringate & 327.20 & 336.62 & 285.92 & 370.81 & 277.93 & 443.89 & $340.39 \pm 55.82$ & 277.93 & 443.89 \\
\hline Epicatechin & 54.90 & 62.58 & 56.08 & 78.81 & 179.29 & 30.67 & $77.05 \pm 47.87$ & 30.67 & 179.29 \\
\hline Syringic acid & 31.49 & 39.53 & 25.16 & 32.33 & 53.07 & 105.86 & $47.91 \pm 27.34$ & 25.16 & 105.86 \\
\hline Catechin & 66.13 & 54.52 & 24.35 & 14.56 & 37.64 & 26.68 & $37.31 \pm 17.92$ & 14.56 & 66.13 \\
\hline 4-coumaric acid & 18.83 & 11.90 & 17.43 & 19.11 & 49.43 & 5.13 & $20.31 \pm 13.91$ & 5.13 & 49.43 \\
\hline Gallic acid & 22.76 & 14.66 & 18.04 & 15.32 & 0.00 & 34.40 & $17.53 \pm 10.27$ & 0.00 & 34.40 \\
\hline Quercetin & 12.26 & 13.23 & 7.53 & 10.67 & 10.39 & 42.77 & $16.14 \pm 12.04$ & 7.53 & 42.77 \\
\hline Apigenin & 13.85 & 15.50 & 19.61 & 33.38 & 1.25 & 7.00 & $15.10 \pm 10.11$ & 1.25 & 33.38 \\
\hline Luteolin & 0.00 & 11.60 & 22.08 & 14.04 & 21.22 & 16.08 & $14.17 \pm 7.34$ & 0.00 & 22.08 \\
\hline Kaempferol & 19.11 & 5.24 & 7.51 & 10.51 & 15.96 & 19.64 & $12.99 \pm 5.58$ & 5.24 & 19.64 \\
\hline Naringenin & 0.00 & 42.41 & 0.00 & 19.82 & 0.77 & 0.00 & $10.50 \pm 15.97$ & 0.00 & 42.41 \\
\hline Formononetin & 3.26 & 0.87 & 4.92 & 10.01 & 9.04 & 17.88 & $7.66 \pm 5.55$ & 0.87 & 17.88 \\
\hline Genistein & 6.61 & 0.00 & 0.00 & 24.00 & 5.40 & 3.36 & $6.56 \pm 8.18$ & 0.00 & 24.00 \\
\hline 3-coumaric acid & 7.03 & 5.85 & 2.40 & 8.38 & 8.66 & 2.72 & $5.84 \pm 2.50$ & 2.40 & 8.66 \\
\hline Daidzein + Pelargonidin & 1.84 & 3.29 & 6.63 & 3.52 & 6.09 & 8.16 & $4.92 \pm 2.19$ & 1.84 & 8.16 \\
\hline 2-coumaric acid & 0.45 & 0.89 & 1.75 & 1.12 & 8.17 & 1.66 & $2.34 \pm 2.64$ & 0.45 & 8.17 \\
\hline Biochanin A & 1.71 & 0.86 & 0.96 & 4.10 & 2.83 & 1.03 & $1.92 \pm 1.19$ & 0.86 & 4.10 \\
\hline Cyanidin & 0.39 & 0.31 & 1.13 & 2.30 & 0.19 & 0.00 & $0.72 \pm 0.79$ & 0.00 & 2.30 \\
\hline Total polyphenols & 587.82 & 619.86 & 501.49 & 672.78 & 687.31 & 766.91 & $639.36 \pm 83.39$ & 501.49 & 766.91 \\
\hline Methyl syringate (\%) & 55.66 & 54.31 & 57.01 & 55.12 & 40.44 & 57.88 & $53.40 \pm 5.92$ & 40.44 & 57.88 \\
\hline
\end{tabular}

(Table 2). Methyl syringate was the most abundant at concentrations ranging from $277.9 \mu \mathrm{g} / \mathrm{g}$ in sample $\mathrm{H} 5$ to $443.9 \mu \mathrm{g} / \mathrm{g}$ in sample $\mathrm{H6}$, representing $40.4 \%$ and $57.9 \%$ of total polyphenols, respectively. In association with the presence of $B$. spinosum pollen, this high level of methyl syringate in Zantaz honey can be exploited as a chemical marker determinant of the authenticity of this honey type against other local or commercial honeys.

It is worth mentioning that the present work is not enough evidence to associate the presence of methyl syringate to Bupleurum spinosum plant. An analysis of the nectar of this will be necessary to establish such relationship. Although, the presence of both markers in a honey samples could be a strong tool to attribute the commercial label: "Zantaz honey".

Concentrations of methyl syringate this high have only been detected before in Manuka, Kanuka and Asphodel honeys. Manuka honey comes from New Zealand and is highly appreciated for its health promoting properties, partially related to their high content in methyl syringate at more than $122.6 \mu \mathrm{g} / \mathrm{g}$ (Patel \& Cichello, 2013; Tuberoso et al., 2009). This monofloral honey is produced from the plant Leptospermun scoparium (Myrtaceae). Even higher contents in methyl syringate, up to $342 \mathrm{mg} / \mathrm{kg}$, have been found in Kanuka honey (Kato et al., 2016). Kanuka honey is produced from Kunzea ericoides (Myrtaceae), a plant very close taxonomically to Leptospermun. Methyl syringate has also been described as a chemical marker for Asphodel honey, a monofloral honey produced from Asphodelus microcarpus (Xanthorrhoeaceae) (Tuberoso et al., 2009). Much lower amounts of methyl syringate, between 0.09 and $5.04 \mathrm{mg} / \mathrm{kg}$, have been found in other honeys, including honeys from robinia, rape, chestnut, clover, dandelion, sunflower, thyme and fir (Tan, Wilkins, Holland, \& McGhie, 1990). Thus, methyl syringate is present in high amounts in a few monofloral honeys produced from plants that are very distant taxonomically. These plants belong to three families in different Orders, namely Order Apiales (Bupleurum), Myrtales (Leptospermum and Kunzea) and Asparagales (Asphodelus).

Epicatechin was the second most abundant polyphenol in Zantaz honey, with an average value of $77.1 \mu \mathrm{g} / \mathrm{g}$. Syringic acid and catechin, which are related to methyl syringate and epicatechin, respectively, followed in abundance. Health promoting properties such as antioxidant and antiproliferative activities have been found in all these polyphenols (Gheena \& Ezhilarasan, 2019; Natarajan et al., 2019; Qu et al., 2020).

While the content in individual polyphenols is used for determination of monofloral origin, the whole phenolic composition constitute a chemical fingerprint that reflects the botanical origin of honey (Bertoncelj et al., 2011).

\subsection{Cellular antiproliferative activity of Zantaz honey}

The THP-1 cell line, derived from a human monocytic leukaemia case, normally grows in suspension unless cells are differentiated to macrophages upon stimulation (Girón-Calle et al., 2010). The assay that has been used to measure the effect of Zantaz honey on cell proliferation is based on the reduction of MTT, by cellular dehydrogenases, to a blue formazan that absorbs at $570 \mathrm{~nm}$ (Lochmann \& Zimmer, 2005). Exposure of THP-1 cells to Zantaz honey for $24 \mathrm{~h}$ caused a dose-dependent increase in cell proliferation of up to $140 \%$ of control as determined using the MTT assay (Fig. 1A, blue line). However, it was apparent, by observation under the microscope, that the number of cells actually decreased after exposure to Zantaz honey. Treatment for $72 \mathrm{~h}$ caused an inhibition of proliferation as determined by the MTT assay that matched a decrease in cell number as observed at the microscope (Fig. 1B, blue line).

It was previously reported that honey interferes with the MTT assay in PC3 and DU145 prostate cancer cells (Abel \& Baird, 2018). Removal of medium and washing of these adherent cells, before addition of MTT, eliminated the interference. The interference was probably due to the presence of reducing sugars and/or phenolic compounds in honey and resulted in an overestimation of cell proliferation using the MTT assay. In order to find out whether Zantaz honey is also interfering with the MTT assay, in our experiments using THP-1 cells, a honey interference control was carried out by assaying honey samples in the absence of cells. All other conditions during incubations and MTT assays were the same than those used during treatment of cells with honey. Results were consistent with those previously reported (Abel \& Baird, 2018), indicating that Zantaz honey caused absorption at $570 \mathrm{~nm}$ used to measure reduced MTT. Red lines in Fig. 1A and 1B shows the effect of different concentrations of Zantaz honey after subtraction of the honey interference controls. It is apparent that honey inhibited proliferation of THP-1 cells after incubation for 24 or $72 \mathrm{~h}$. Interference by honey was much higher in the shorter incubation, indicating disappearance of interfering components in honey with incubation time.

Abel \& Baird (2018) suggested that interference of honey with the MTT assay was due to reduction of MTT by reducing sugars and proved it by using a sugar solution mimicking the sugar composition of the specific honey that they used. They reported that the "artificial honey" so prepared increased MTT absorbance by $57 \%$. We did the same for 


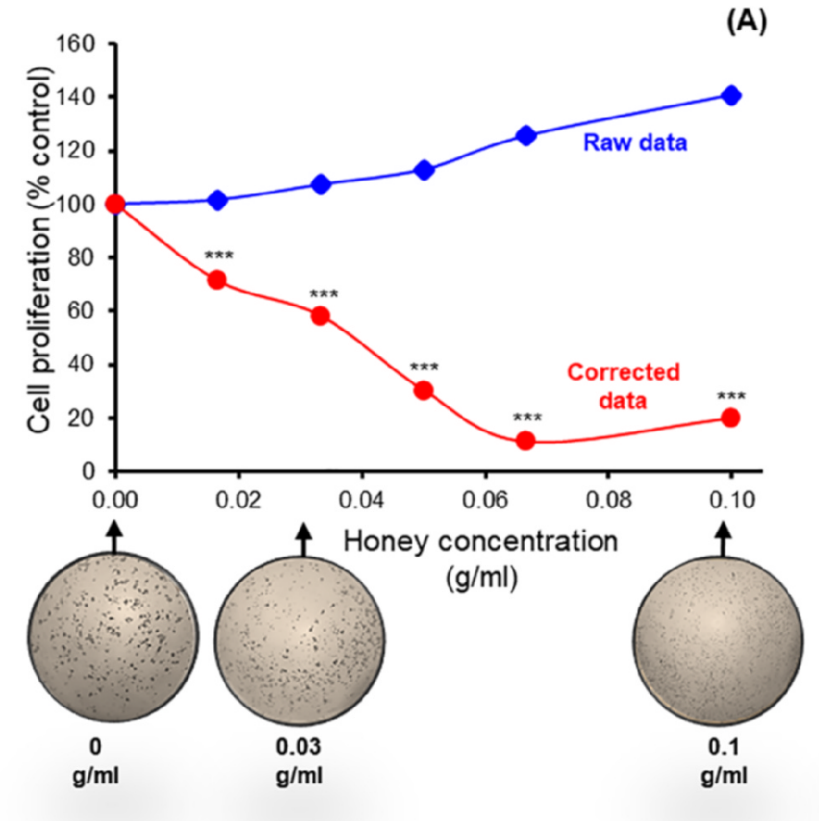

(C)
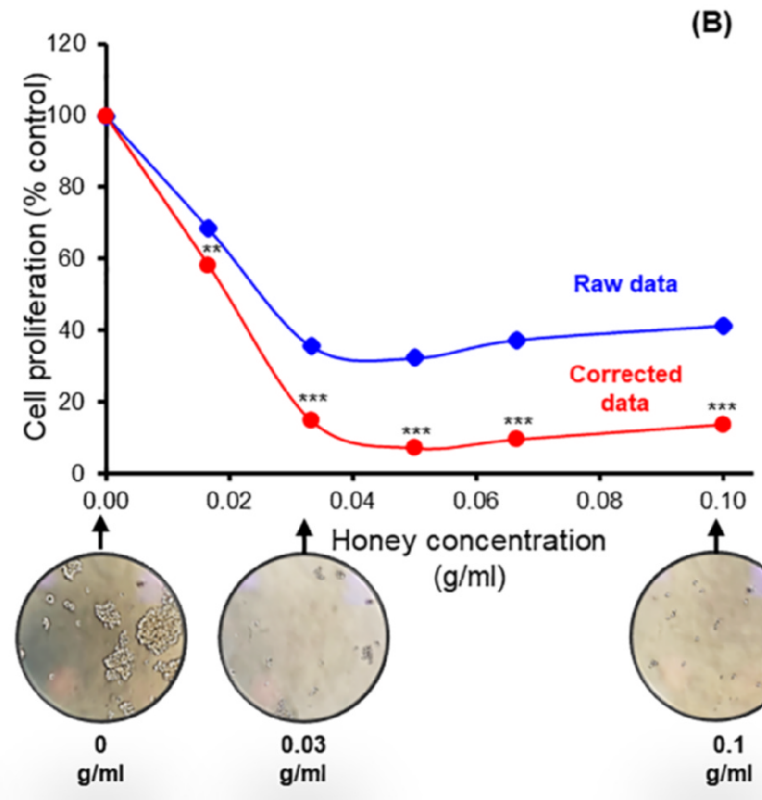

$(\mathrm{g} / \mathrm{ml})$

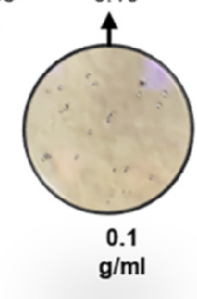

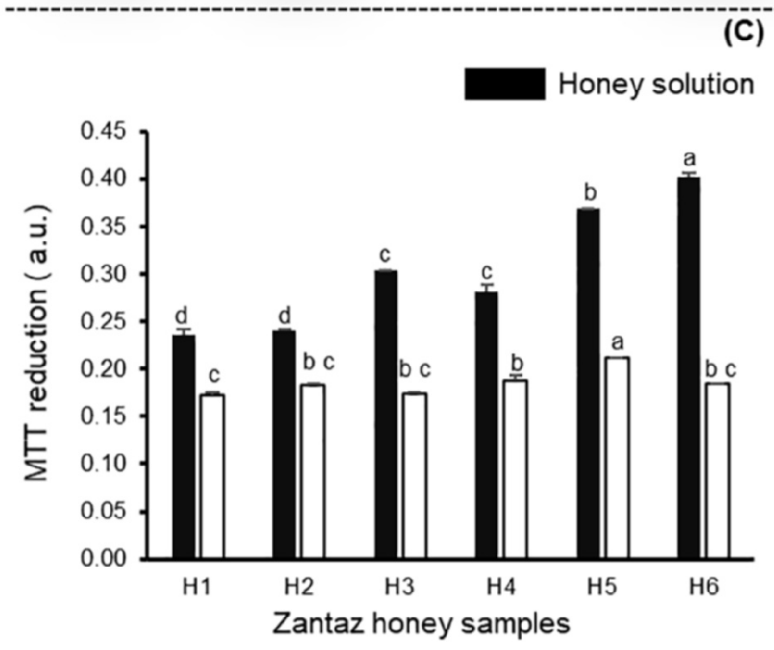

(D)

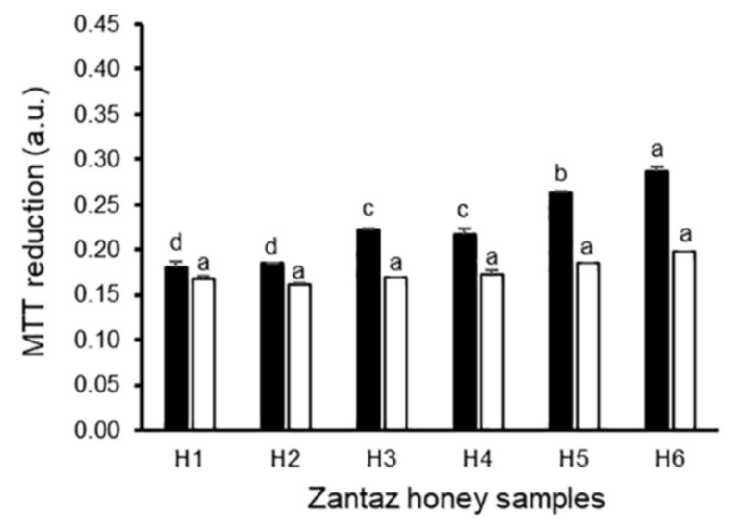

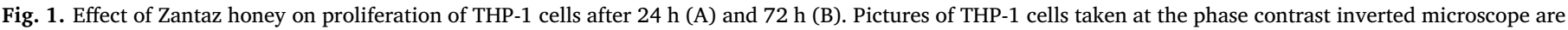

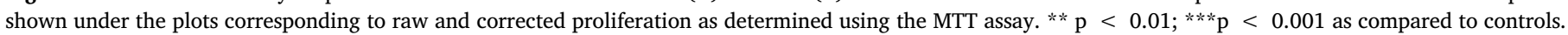

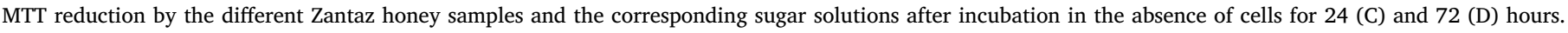
Columns with the same letter are not significantly different $(\mathrm{p}<0.05)$.

Zantaz honey and results are shown in Fig. 1c and 1d. Data indicate that sugars account for most, but not all of absorbance characteristic of the reduced MTT formazan. Absorbance by components other than sugars, such as polyphenols, varies greatly between different Zantaz honey samples and it was attenuated by a longer incubation time.

The antiproliferative activity of the honey samples (concentration versus control $\%$ values) and $\mathrm{IC}_{50}$ values (honey concentration that inhibits proliferation of THP-1 cells by $50 \%$ ) were calculated for each of the six honey samples that were collected for this study (Fig. 2A and 2B). Little variability was observed amongst the analysed samples suggesting that the antiproliferative components in Zantaz honey samples are present in all honey samples at similar concentration. Sample H1 was the most active sample with a value of $31 \pm 0.58 \mathrm{mg}$ / $\mathrm{mL}$ while $\mathrm{H} 5$ was the less active sample ( $\mathrm{IC}_{50}=46 \pm 2.82 \mathrm{mg} / \mathrm{mL}$ ). It is worth mentioning that this sample had the lowest percentage of methyl syringate $(40.44 \%)$, while all other samples had values above $50 \%$.

To our knowledge, this is the first report on the antiproliferative activity of honey on the monocytic leukaemia THP-1 cell line. There are some reports of the antiproliferative activity of honey on other cancer cells, an activity that is attributed to bioactive components mostly derived from the floral nectars brought to the hive (Afrin et al., 2020). Most important bioactive compounds in honey are polyphenols. For example, Tualang honey inhibited proliferation of K562 and MV4-11 leukaemia cells (Nik Man et al., 2015). This Malaysian honey is collected from beehives in Tualang trees (Koompassia excelsa) and is rich in polyphenols that are also present in Zantaz honey, including syringic acid, p-coumaric acid, catechin, luteolin and apigenin (Kishore, Halim, Syazana, \& Sirajudeen, 2011). Also, Manuka honey, rich in methyl syringate, inhibited proliferation of murine melanoma (B16.F1), colorectal carcinoma (CT26) and human breast cancer (MCF-7) cells. This effect was dependent on apoptosis with activation of caspase 3 and 9, reduced Bcl-2 expression and DNA fragmentation (Patel \& Cichello, 2013). Interestingly, Manuka honey decreased tumour volume in a mouse melanoma model by increasing apoptosis and reduced colonic inflammation in inflammatory bowel disease in rats (Alvarez-Suarez, Gasparrini, Forbes-Hernández, Mazzoni, \& Giampieri, 2014). 

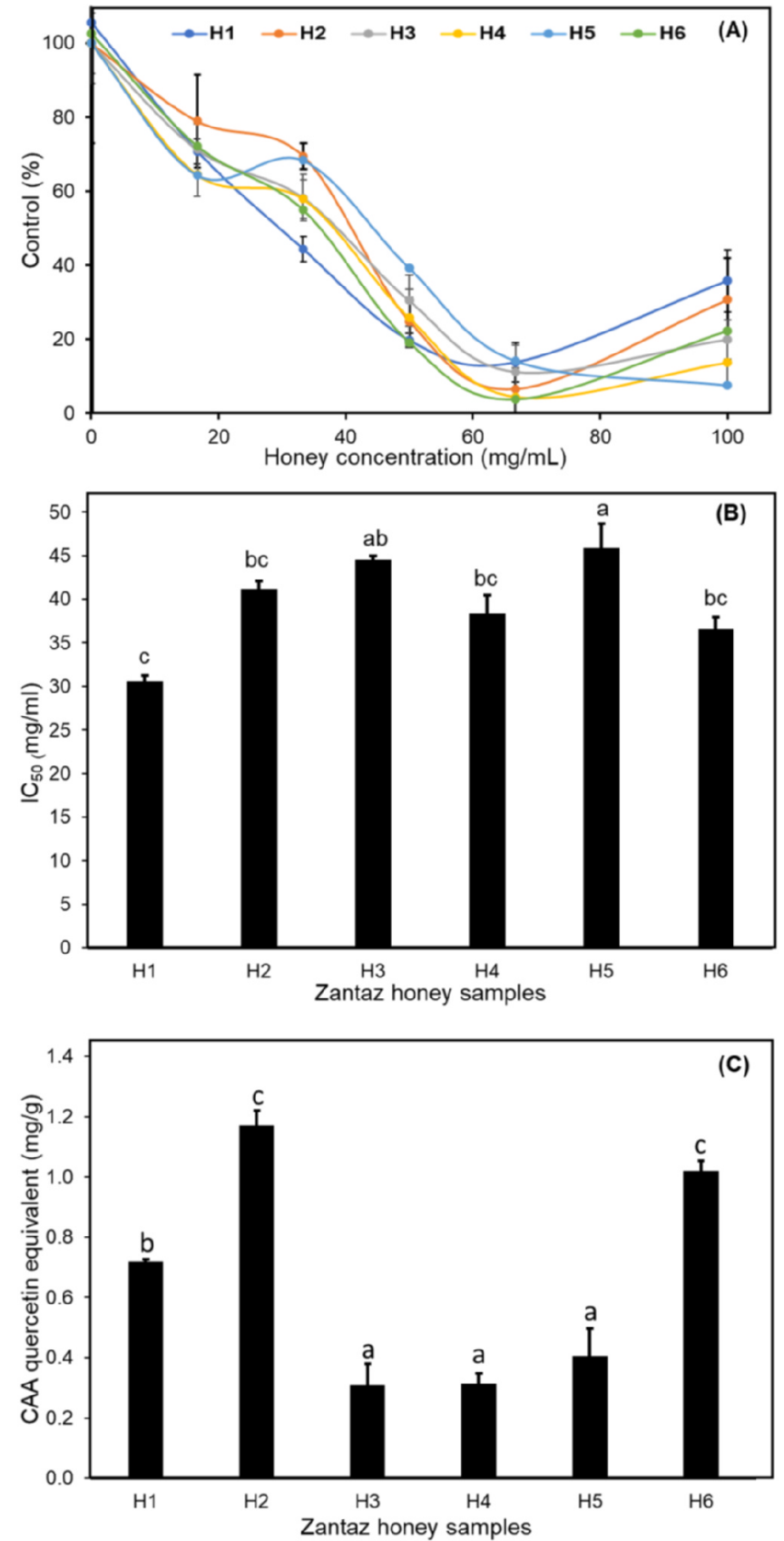

Fig. 2. (A) Proliferation of THP-1 cells (\% control) under exposure to increasing concentrations of honey after $24 \mathrm{~h}$. (B) $\mathrm{IC}_{50}$ of the antiproliferative activity of the six honey samples. (C) Antioxidant activity of Zantaz honey samples in Caco-2 cells, expressed as cellular antioxidant activity (CAA) quercetin equivalents $\mathrm{mg} / \mathrm{g}$ of honey. Samples with same letters are not significantly different $(\mathrm{p}<0.05)$.

\subsection{Cellular antioxidant activity of Zantaz honey}

Food rich in antioxidants, such as the Mediterranean diet, can prevent oxidative damage to cells, a process that has been involved in many diseases including cardiovascular diseases, neurodegenerative diseases and cancer (Bach-Faig, Berry, Lairon, Reguant, Trichopoulou, Dernini, Medina, Battino, et al., 2011). The cellular antioxidant capacity (CAC) of Zantaz honey was determined as the inhibition of oxidation of the cell permeant dichlorofluorescin probe to fluorescent dichlorofluorescein in the presence of a free radical generator. CAC in the six samples of Zantaz honey varied between 0.3 and 1.2 quercetin equivalents (Fig. 2 C). Zantaz honeys samples were more variable in their antioxidant activity than in their antiproliferative activity. An explanation is that antioxidant activity involves more compounds than the antiproliferative activity, and hence is more variable due to the differences in total polyphenols composition between Zantaz honey samples.

Three groups can be established according to statistically significant differences in CAC: samples $\mathrm{H} 2$ and $\mathrm{H} 6$ with the highest CAC, $\mathrm{H} 1$ with an intermediate CAC and $\mathrm{H} 3, \mathrm{H} 4$ and $\mathrm{H} 5$ with the lowest CAC.

In both cell-based assays, the activity is mostly due to the presence of phenolic compounds, such as methyl syringate. Similarly, in Asphodelus honeys, antioxidant activities in vitro and in vivo were related to the high phenolic content including methyl syringate (Jubri, Rahim, \& Aan, 2013; Stephens et al., 2010).

\subsection{Correlation of Zantaz honey polyphenol composition with antiproliferative and antioxidant activities using multivariate analysis}

Although honey is a complex mixture of many components of different nature, polyphenols are responsible for most of its biological activity (Afrin et al., 2020). PCA of polyphenol composition, antiproliferative activity and antioxidant capacity has been carried out in order to determine which may be the specific polyphenols responsible for these activities. Polyphenols that were at concentrations above $10 \mu \mathrm{g} / \mathrm{g}$ were used in the multivariate analysis. Melanoidins and the colour of honey were also used in the PCA to determine whether it played a role in the interference of honey in the MTT assay. MTT interference was also considered a variable, together with antiproliferative activity and cellular antioxidant capacity, to complete the input of the PCA. The resulting PCA graphic is shown in Fig. 3.

The first two principal components accounted for $64.78 \%$ of the variance observed in the raw data. Considering PC1, more than half of the components correlated negatively with it, forming a group that includes quercetin, syringic acid, kaempferol, methyl syringate, catechin and gallic acid, in addition to colour and melanoidins. This cluster shows a positive correlation with the three variables (antiproliferative activity, $1 / \mathrm{IC}_{50}$, antioxidant activity, CAA and the MTT interference). This is in agreement with previous reports describing a positive correlation between antioxidant and antiproliferative activities

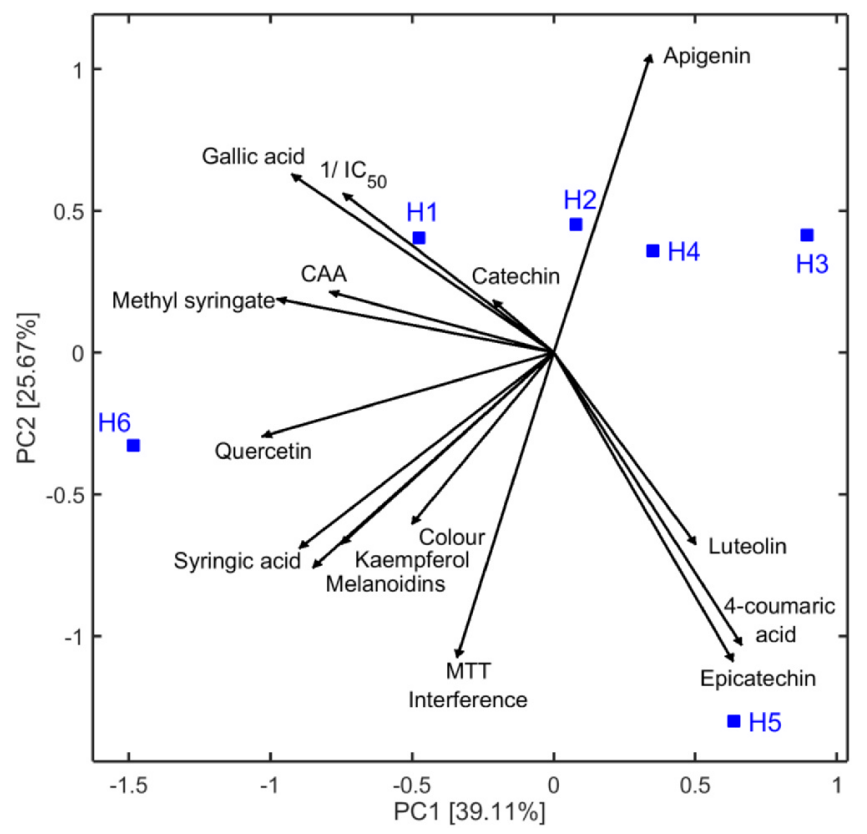

Fig. 3. Principal component analysis (PCA) using the phenolic composition and the evaluated biological activities of the analysed Zantaz honey samples. 
and polyphenols composition. Hence, the antioxidant and antiproliferative activities of polyphenols are well established (Ahmed \& Othman, 2013; J. M. Alvarez-Suarez, Tulipani, Romandini, Bertoli, \& Battino, 2010; Cianciosi et al., 2018; Jaganathan \& Mandal, 2009; Jubri et al., 2013). Polyphenols also represent the most important determinant of honey colour (Elamine et al., 2018). Melanoidins, the final products of Maillard reactions, are also known to inhibit proliferation of a number of transformed cells, including rhabdomyosarcoma-medulloblastoma, glioma, breast, colon and lung cells (Langner \& Rzeski, 2014).

A second group of polyphenols was formed by luteolin, 4-coumaric acid and epicatechin. Although these polyphenols are expected to have antioxidant and antiproliferative properties, a negative correlation between their contents in Zantaz honey and the biological activities was observed. These apparently contradictory results are explained by the existing correlation between the polyphenols contents (Fig. 3). Hence, a negative correlation between polyphenols contents in group 1 (negative part of PC1) and those in the second (positive part of PC1) is observed. Considering that the first cluster showed highest biological activities, the negative correlation between polyphenols content in both groups is also translated to their biological activities. This negative correlation between phenolic contents has a reasonable explanation. Honeybees visit different floral sources to make one honey type. If one nectar source is the most abundant, such as B. spinosum in Zantaz honey fields, phenolic contents from this plant, will correlate negatively with the phenolics contents from other minority floral sources.

Considering the second principal component (PC2), with the exception of apigenin, catechin, gallic acid and methyl syringate, all parameters contributed to the interference in the MTT assay of honey samples. PC2 also shows that methyl syringate and gallic acid were main contributors of the biological activities of Zantaz honey. Considering both PC axis, also methyl syringate and gallic acid were the main compounds responsible of the antiproliferative and antioxidant activities.

The PCA also shows that Zantaz honey populations H1 was the best one with respect to those biological activities and high contents on methyl syringate and gallic acid, while on the opposite side of the graphic was population $\mathrm{H} 5$ with worse biological activities and low amounts of methyl syringate and gallic acid.

While the content in catechin correlated positively (little contribution to PC1) with the antiproliferative and antioxidant activities, apigenin correlated positively only with the antiproliferative activity. There was an inverse correlation between the content in catechin/ apigenin and interference in the MTT assay. Catechin is a colourless compound (Pou, Paul, \& Malakar, 2019) and apigenin gives a yellow colour (Mukherjee, 2019), apparently resulting in a reduced absorption in the MTT assay.

\section{Conclusion}

In conclusion, Zantaz honey is a traditional local product that has interesting health promoting properties such as antioxidant and antiproliferative activities. This honey is characterized by its very high content in methyl syringate, a polyphenol that has been previously found in a few other honeys. The multivariate analysis of results showed a positive correlation of methyl syringate contents and the biological activities. The characterization of Zantaz honey as a healthpromoting food due to its antiproliferative and antioxidant activities should increase its commercial value, which would have a very positive economic impact on the rural communities of Morocco where it is produced.

\section{CRediT authorship contribution statement}

Youssef Elamine: Conceptualization, Investigation, Data curation, Writing - original draft. Badiaa Lyoussi: Conceptualization, Writing - original draft. Maria. G. Miguel: Methodology, Supervision. Ofélia Anjos: Investigation, Data curation. Letícia Estevinho: Methodology, Investigation. Manuel Alaiz: Investigation. Julio Girón-Calle: Supervision, Writing - review \& editing. Jesús Martín: Investigation. Javier Vioque: Conceptualization, Funding acquisition, Project administration, Writing - review \& editing.

\section{Declaration of Competing Interest}

The authors declare that they have no known competing financial interests or personal relationships that could have appeared to influence the work reported in this paper.

\section{Acknowledgments}

This research was funded by the C.S.I.C. Programme for Scientific Cooperation for Development (Programme I-COOP + 2018). Thanks are due to Fernando Reyes (Fundación MEDINA, Granada, Spain) for the identification of polyphenols in Zantaz honey.

Centro de Estudos Florestais is a research unit funded by FCT -Foundation for Science and Technology, under the Project (UIDB/ 00239/2020)

\section{References}

Abel, S. D. A., \& Baird, S. K. (2018). Honey is cytotoxic towards prostate cancer cells but interacts with the MTT reagent: Considerations for the choice of cell viability assay. Food Chemistry, 241, 70-78. https://doi.org/10.1016/j.foodchem.2017.08.083.

Afrin, S., Haneefa, S. M., Fernandez-Cabezudo, M. J., Giampieri, F., Al-Ramadi, B. K., \& Battino, M. (2020). Therapeutic and preventive properties of honey and its bioactive compounds in cancer: An evidence-based review. Nutrition Research Reviews, 33(1), 50-76. https://doi.org/10.1017/S0954422419000192.

Ahmed, S., \& Othman, N. H. (2013). Honey as a Potential Natural Anticancer Agent: A Review of Its Mechanisms. Evidence-Based Complementary and Alternative Medicine, 2013, 1-7. https://doi.org/10.1155/2013/829070.

Alvarez-Suarez, J., Gasparrini, M., Forbes-Hernández, T., Mazzoni, L., \& Giampieri, F. (2014). The Composition and Biological Activity of Honey: A Focus on Manuka Honey. Foods, 3(May), 420-432. https://doi.org/10.3390/foods3030420.

Alvarez-Suarez, J. M., Tulipani, S., Romandini, S., Bertoli, E., \& Battino, M. (2010). April 8). Contribution of honey in nutrition and human health: A review. Mediterranean Journal of Nutrition and Metabolism. Springer.. https://doi.org/10.1007/s12349-0090051-6.

Bach-Faig, A., Berry, E. M., Lairon, D., Reguant, J., Trichopoulou, A., Dernini, S., .. Padulosi, S. (2011). Mediterranean diet pyramid today. Science and cultural updates. Public Health Nutrition, 14(12A), 2274-2284. https://doi.org/10.1017/ S1368980011002515.

Bach-Faig, A., Berry, E. M., Lairon, D., Reguant, J., Trichopoulou, A., Dernini, S., ... SerraMajem, L. (2011). Mediterranean diet pyramid today. Science and cultural updates. Public Health Nutrition, 14(12A), 2274-2284. https://doi.org/10.1017/ S1368980011002515.

Bertoncelj, J., Polak, T., Kropf, U., Korošec, M., \& Golob, T. (2011). LC-DAD-ESI/MS analysis of flavonoids and abscisic acid with chemometric approach for the classification of Slovenian honey. Food Chemistry, 127(1), 296-302. https://doi.org/10. 1016/j.foodchem.2011.01.003.

Bogdanov, S., Martin, P., Lüllmann, C., Borneck, R., Flamini, Ch. C., Morlot, M., \& Ivanov, T. (1997). Harmonized methods of the International Honey commission (IHC) responsible for the methods, 5, 1-59.

Bogdanov, S., Ruoff, K., \& Oddo, L. P. (2004). Physico-chemical methods for the characterisation of unifloral honeys : A review. Apidologie, 35, 4-17. https://doi.org/10 1051/apido.

Chen, C., Wang, L., Wang, R., Luo, X., Li, Y., Li, J., ... Chen, Z. (2018). Phenolic contents, cellular antioxidant activity and antiproliferative capacity of different varieties of oats. Food Chemistry, 239, 260-267. https://doi.org/10.1016/j.foodchem.2017.06. 104.

Cianciosi, D., Forbes-Hernández, T. Y., Afrin, S., Gasparrini, M., Reboredo-Rodriguez, P., Manna, P. P., ... Battino, M. (2018). September 11). Phenolic compounds in honey and their associated health benefits: A review. Molecules. MDPI AG.. https://doi.org/ $10.3390 /$ molecules 23092322 .

COUNCIL DIRECTIVE Official Journal of the European (2002). Communities, 47-52 2001/ 110/EC of 20 December 2001 relating to honey.

Elamine, Y., Aazza, S., Lyoussi, B., Dulce Antunes, M., Estevinho, L. M., Anjos, O., ... Miguel, M. G. (2018). Preliminary characterization of a Moroccan honey with a predominance of Bupleurum spinosum pollen. Journal of Apicultural Research, 57(1), 153-165. https://doi.org/10.1080/00218839.2016.1265759.

Elamine, Y., Lyoussi, B., Anjos, O., Estevinho, L. M., Aazza, S., Carlier, J. D., ... Miguel, M. G. (2019). Zantaz honey "monoflorality": Chemometric applied to the routinely assessed parameters. LWT - Food Science and Technology, 106, 29-36. https://doi.org/ 10.1016/j.lwt.2019.02.039. 
Gheena, S., \& Ezhilarasan, D. (2019). Syringic acid triggers reactive oxygen species-mediated cytotoxicity in HepG2 cells. Human \& Experimental Toxicology, 38(6), 694-702. https://doi.org/10.1177/0960327119839173.

Girón-Calle, J., Alaiz, M., \& Vioque, J. (2010). Effect of chickpea protein hydrolysates on cell proliferation and in vitro bioavailability, 43, 1365-1370. https://doi.org/10.1016/j. foodres.2010.03.020.

Jaganathan, S. K., \& Mandal, M. (2009). Antiproliferative Effects of Honey and of Its Polyphenols: A Review. Journal of Biomedicine and Biotechnology, 2009, 1-13. https:// doi.org/10.1155/2009/830616.

Jubri, Z., Rahim, N. B. A., \& Aan, G. J. (2013). Manuka honey protects middle-aged rats from oxidative damage. Clinics, 68(11), 1446.

Kato, Y., Fujinaka, R., Juri, M., Yoshiki, Y., Ishisaka, A., Kitamoto, N., ... Ishikawa, H. (2016). Characterization of a Monoclonal Antibody against Syringate Derivatives: Application of Immunochemical Detection of Methyl Syringate in Honey. Journal of Agricultural and Food Chemistry, 64(33), 6495-6501. https://doi.org/10.1021/acs. jafc.6b01328.

Kishore, R. K., Halim, A. S., Syazana, M. S. N. S. N., \& Sirajudeen, K. N. S. N. S. (2011). Tualang honey has higher phenolic content and greater radical scavenging activity compared with other honey sources. Nutrition Research, 31(4), 322-325. https://doi. org $/ 10.1016 /$ j nutres. 2011.03.001.

Langner, E., \& Rzeski, W. (2014). Biological Properties of Melanoidins: A Review. International Journal of Food Properties, 17(2), 344-353. https://doi.org/10.1080/ 10942912.2011.631253.

Lochmann, D., \& Zimmer, A. (2005). A practical note on the use of cytotoxicity assays, 288, 369-376. https://doi.org/10.1016/j.ijpharm.2004.09.018.

Louveaux, J., Maurizio, A., \& Vorwohl, G. (1978). Methods of melissopalynology. Bee World, 5(3), 139-153. https://doi.org/10.1080/0005772X.1978.11097714.

Missio, P., Gauche, C., Gonzaga, L. V., Carolina, A., \& Costa, O. (2016). Honey : Chemical composition, stability and authenticity Honey: Chemical composition, stability and authenticity. Food Chemistry, 196(April), 309-323. https://doi.org/10.1016/j. foodchem.2015.09.051.

Mukherjee, P. K. (2019). Bioactive Phytocomponents and Their Analysis. Quality Control and Evaluation of Herbal Drugs. https://doi.org/10.1016/b978-0-12-813374-3. 00007-7.

Natarajan, S., Chandran, S., ... S. K.-C. N. \&, \& 2019, U. (2019). Versatile Health Benefits of Catechin from Green Tea (Camellia sinensis). Current Nutrition \& Food Science, 15(1), 3-10. https://doi.org/10.2174/1573401313666171003150503.

Nik Man, N. M. K., Hassan, R., Ang, C. Y., Abdullah, A. D., Mohd Radzi, M. A. R., \& Sulaiman, S. A. (2015). Antileukemic Effect of Tualang Honey on Acute and Chronic Leukemia Cell Lines. BioMed Research International, 2015, 1-7. https://doi.org/10.
$1155 / 2015 / 307094$.

Pasquini, B., Goodarzi, M., Orlandini, S., Beretta, G., Furlanetto, S., \& Dejaegher, B. (2014). Geographical characterisation of honeys according to their mineral content and antioxidant activity using a chemometric approach. International Journal of Food Science \& Technology, 49(5), 1351-1359. https://doi.org/10.1111/ijfs.12436.

Patel, S., \& Cichello, S. (2013). Manuka honey: An emerging natural food with medicinal use. Natural Products and Bioprospecting, 3(4), 121-128. https://doi.org/10.1007/ s13659-013-0018-7.

Pérez-Victoria, I., Martín, J., \& Reyes, F. (2016). Combined LC/UV/MS and NMR Strategies for the Dereplication of Marine Natural Products. Planta Medica, 82(9-10), 857-871. https://doi.org/10.1055/s-0042-101763.

Porcza, L., Simms, C., \& Chopra, M. (2016). Honey and Cancer: Current Status and Future Directions. Diseases, 4(4), 30. https://doi.org/10.3390/diseases4040030.

Pou, K. R. J., Paul, S. K., \& Malakar, S. (2019). Industrial processing of CTC black tea. Caffeinated and Cocoa Based Beverages: Volume 8. The Science of Beverages. Elsevier Inc. https://doi.org/10.1016/B978-0-12-815864-7.00004-0.

Qu, Z., Liu, A., Li, P., Liu, C., Xiao, W., Huang, J., ... Zhang, S. (2020). Advances in physiological functions and mechanisms of (-)-epicatechin. Critical Reviews in Food Science and Nutrition, 1-23. https://doi.org/10.1080/10408398.2020.1723057.

Salamanca, L. X. A., \& Torres, D. M. C. (2017). Estudio cromatográfico por HPLC-UV, cuantificación de fenoles, flavonoides y evaluación de la capacidad antioxidante en miel de abejas. Thesis.

Stephens, J. M., Schlothauer, R. C., Morris, B. D., Yang, D., Fearnley, L., Greenwood, D. R., \& Loomes, K. M. (2010). Phenolic compounds and methylglyoxal in some New Zealand manuka and kanuka honeys. Food Chemistry, 120(1), 78-86. https://doi.org/ 10.1016/j.foodchem.2009.09.074.

Tan, S. T., Wilkins, A. L., Holland, P. T., \& McGhie, T. K. (1990). Extractives from New Zealand Honeys. 3. Unifloral Thyme and Willow Honey Constituents. Journal of Agricultural and Food Chemistry, 38(9), 1833-1838. https://doi.org/10.1021/ jf00099a010.

Tuberoso, C. I. G., Bifulco, E., Jerkovic, I., Caboni, P., Cabras, P., \& Floris, I. (2009) Methyl syringate: A chemical marker of asphodel (asphodelus microcarpus salzm. et viv.) monofloral honey. Journal of Agricultural and Food Chemistry, 57(9), 3895-3900. https://doi.org/10.1021/jf803991j.

Wan, H., Liu, D., Yu, X., Sun, H., \& Li, Y. (2015). A Caco-2 cell-based quantitative antioxidant activity assay for antioxidants. Food Chemistry, 175, 601-608. https://doi. org/10.1016/j.foodchem.2014.11.128.

Wang, H., \& Joseph, J. A. (1999). Quantifying cellular oxidative stress by dichlorofluorescein assay using microplate reader. Free Radical Biology and Medicine, 27(5-6), 612-616. https://doi.org/10.1016/S0891-5849(99)00107-0. 